\title{
FEATURE EXTRACTION OF DESIS AND PRISMA HYPERSPECTRAL REMOTE SENSING DATASETS FOR GEOLOGICAL APPLICATIONS
}

\author{
Prateek Tripathi ${ }^{\text {a, }}$, Rahul Dev Garg a \\ ${ }^{a}$ Geomatics Engineering Group, Department of Civil Engineering, Indian Institute of Technology, Roorkee, Uttarakhand, India, \\ 247667 - (ptripathi, rdgarg)@ce.iitr.ac.in
}

Commission VI, WG VI/4

KEY WORDS: Hyperspectral Remote Sensing, Feature Extraction, Data Dimensionality Reduction, DESIS, PRISMA, Minerals

\begin{abstract}
:
With the recent launch of advanced hyperspectral satellites with global coverage, including DESIS and PRISMA, a massive volume of high spectral resolution data is available. This work is focused on the spectral analysis and implementation of feature extraction or data dimensionality reduction techniques on both newly available datasets for geological interpretation. Three of the best feature extraction algorithms, Principal Component Analysis (PCA), Minimum Noise Fraction (MNF), and Independent Component Analysis (ICA), were tested for lithological mapping for the Rajasthan state of India. The present work demonstrates the advantage of the feature extraction algorithm in geological mapping and interpretability as it shows the excellent performance for these datasets. The narrowband ratios for the clay minerals, dolomite, kaolinite, amphiboles, and Al-OH are generated using the PCA and MNF components. All of these band ratios were compared with the Lithological Map available. It is concluded that PCA is the first choice for feature-based lithological classification of hyperspectral remote sensing data. ICA is giving some impressive results which can be explored further. DESIS and PRISMA have a $30 \mathrm{~km}$ swath, finer spectral resolution, and high signal-to-noise ratio, which shows much potential in lithological mapping over the parts of northern India. It is suggested to use advanced feature extraction algorithms with recently launched hyperspectral data for accurate and updated mineral mapping over a sizeable geological importance area.
\end{abstract}

\section{INTRODUCTION}

The high-quality spectral information in a hyperspectral image can better classify and identify the minerals in a mineral-rich area. Meanwhile, Hyperspectral datasets with hundreds of bands come with the curse of inherent dimensionality. A large number of redundant bands can affect the quality of interpretation and classification of the hyperspectral datasets for various applications. High-dimensional datasets have many mathematical challenges and new opportunities and are platforms for developing a new dimensionality algorithm. High data dimensionality covers a significant volume on the disk, increasing with the further processing steps (van der Meer et al., 2012). From the geological point of view, it is necessary to reduce the unnecessary or redundant bands to enhance those bands having diagnostic absorption features of some specific minerals (Gupta and Venkatesan, 2020; Samani et al., 2020; Shirmard et al., 2020). Previously, feature extraction or data dimensionality reduction methods were extensively used for mineral mapping using spaceborne and airborne hyperspectral datasets like Hyperion and AVIRIS (Boardman and Kruse, 1994; Uddin et al., 2020). Recently launched PRISMA and DESIS datasets with good spectral quality in bandwidth and SNR can prove to be a boon for geoscientists in mapping the remote and geologically rich areas on Earth's surface. These datasets will give good results after applying feature extraction techniques thanks to comparative better spectral quality.

Dimensionality reduction techniques are usually applied during pre-processing of the hyperspectral image to remove redundant bands and secure the actual information in a low-dimensional subspace (Richards and Richards, 1999). This work discusses linear data dimensionality reduction methods to deal with high volume hyperspectral data (Pour et al., 2019).
This work focuses on applying linear data dimensionality reduction techniques to newly launched hyperspectral datasets: PRISMA and DESIS. Here the analysis from the results of Principal component analysis (PCA), Minimum noise fraction (MNF), and Independent component analysis (ICA) is discussed for PRISMA and DESIS hyperspectral datasets to interpret the geology of the study area. Later few narrowband ratios developed in the VNIR (Visible to Near-Infrared) and SWIR (Short wave Infrared) range using PRISMA hyperspectral datasets to check the mineral abundance (Kalinowski and Oliver, 2004). These narrowband ratios are developed initially for ASTER datasets, but they have been transformed to narrowband ratios suitable for PRISMA hyperspectral datasets in this work.

\subsection{Principal Component Analysis}

In Digital image processing techniques, PCA is mathematically defined as an orthogonal linear transformation that transforms the hyperspectral image data to a new coordinate system in which the greatest variance by some projection or rotation of the data comes to lie on the first coordinate (also known as the first principal component: PC), the second greatest variance on the second coordinate, and so on (Harsanyi and Chang, 1994). The principal component analysis represents the low dimensional form of high dimensional datasets by decomposing the matrix (pixels in the image) to different components based on either covariance or correlation (Rodarmel and Shan, 2002). PCA includes centralizing of image data (pixels value), similarity analysis using covariance or correlation, and decomposition using either Eigenvalue decomposition (EVD) or singular value decomposition (SVD). Here in this work, EVD is used (Chuvieco, 2016). 


\subsection{Minimum Noise Fraction}

MNF uses PCA twice to decorate and rescale the noise present in the data, and the second rotation uses the principal components obtained after noise whitening the data. The inherent dimensionality of the data is checked by evaluating the final eigenvalues and the associated images. The hyperspectral data space or new subspace after two PCA is divided into two parts with large eigenvalues and coherent Eigen images in one and a complementary part with noise-dominated images. MNF separates the data's noise, thus contributing to improved spectral processing results (Green et al., 1988).

\subsection{Independent Component Analysis}

ICA utilizes higher-order statistics to transform a large number of bands in a hyperspectral image to mutually independent components with no prior information about spectral mixing. ICA transform is based on the non-Gaussian assumption of the independent variables and utilizes higher-order statistics to uncover the meaningful features in hyperspectral datasets of non-Gaussian in nature. IC transformation successfully reveals the elements of interest even no matter how small the area they occupied in the pixels of the hyperspectral image (Hyvarinen, 1999; Hyvärinen and Oja, 2000).

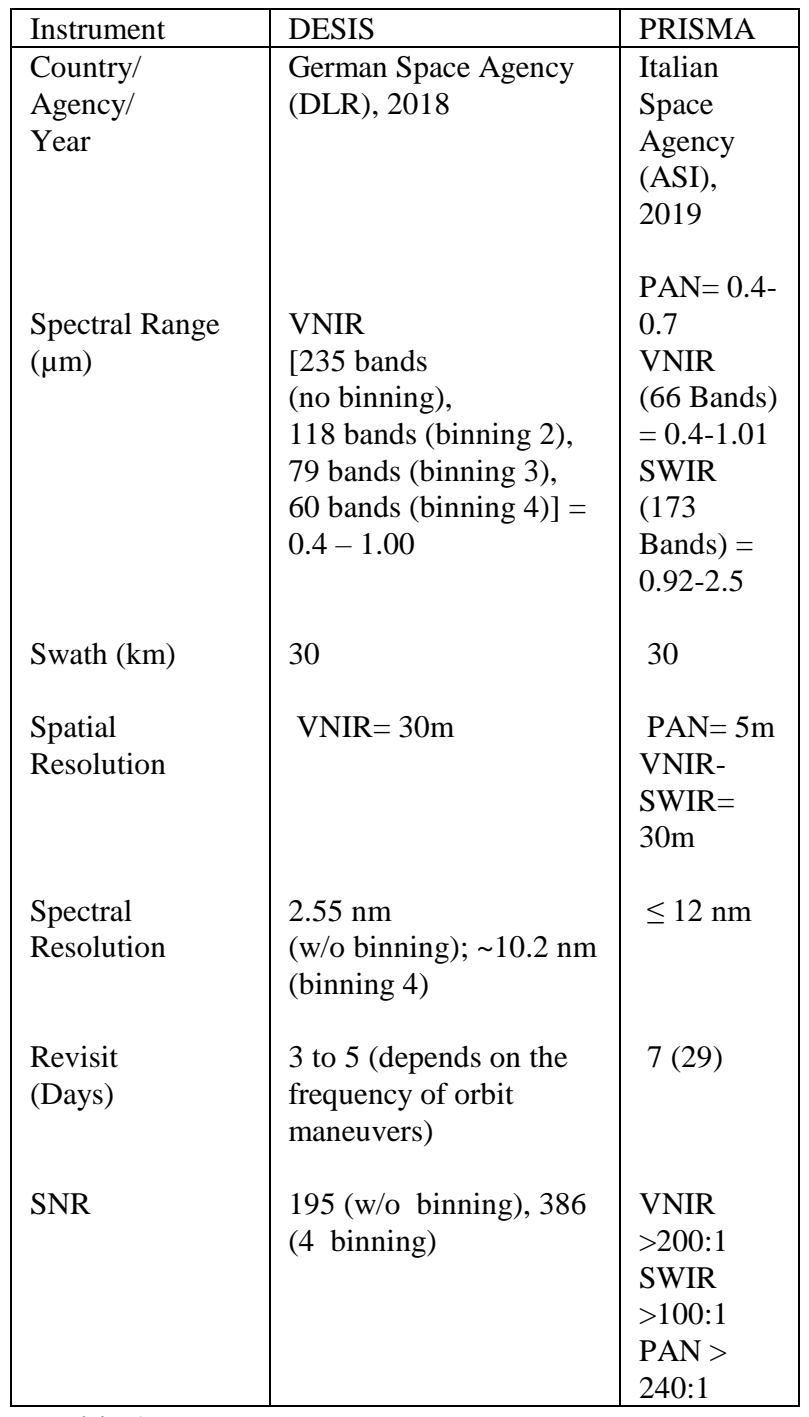

Table 1. Specifications for DESIS and PRISMA datasets

\section{DATASETS}

This work utilizes the DESIS and PRISMA hyperspectral data. DESIS stands for DLR Earth Sensing Imaging Spectrometer, developed by the German Aerospace Center and Teledyne Brown Engineering (Kerr et al., 2016; Krutz et al., 2019). DESIS is a hyperspectral push-broom imaging spectrometer covering the Visible and Near Infrared (VNIR) optical spectral region $(400-1000 \mathrm{~nm})$ with an altitude of $400 \pm 5 \mathrm{~km}$. DESIS datasets are provided with four different spectral binning modes $(0-4)$. The pixel size is $30 \mathrm{~m}$, and the image tile size is 30 $\mathrm{kmX} 30 \mathrm{~km}$. DESIS is installed on the MUSES (Multi-User System for Earth Sensing) platform onboard the International Space Station. DESIS data can be tasked to acquire hyperspectral images for user-defined AOI (Area of Interest). L2A datasets (orthorectified surface reflectance) for DESIS acquired on $7^{\text {th }}$ December 2020 (Banswara) are used in this study.

The PRISMA is a push-broom imaging spectrometer (or hyperspectral imager) to capture images in a series of contiguous spectral bands from 400 to $2500 \mathrm{~nm}$ with an altitude reference of $625 \mathrm{~km}$ (Loizzo et al., 2018; Stefano et al., 2013). The PRISMA, with a daily imaging capability of $\sim 200,000 \mathrm{~km}^{2}$, can deliver hyperspectral imagery for a broad area. PRISMA has a wider swath $(30 \mathrm{~km})$ and temporal frequency (7-14 days) as compared to Hyperion (7.5 km and 14-30 days). DESIS has a slightly better SNR (195) ratio as compared to PRISMA (200). This study utilizes L2D datasets (at surface reflectance and geocoded) of PRISMA acquired on $21^{\text {st }}$ February 2020 (Banswara). Table 1 enlists the sensor specifications for DESIS and PRISMA. DESIS and PRISMA are the only sensors providing "GLOBAL" hyperspectral imageries in recent times.

\section{STUDY AREA}

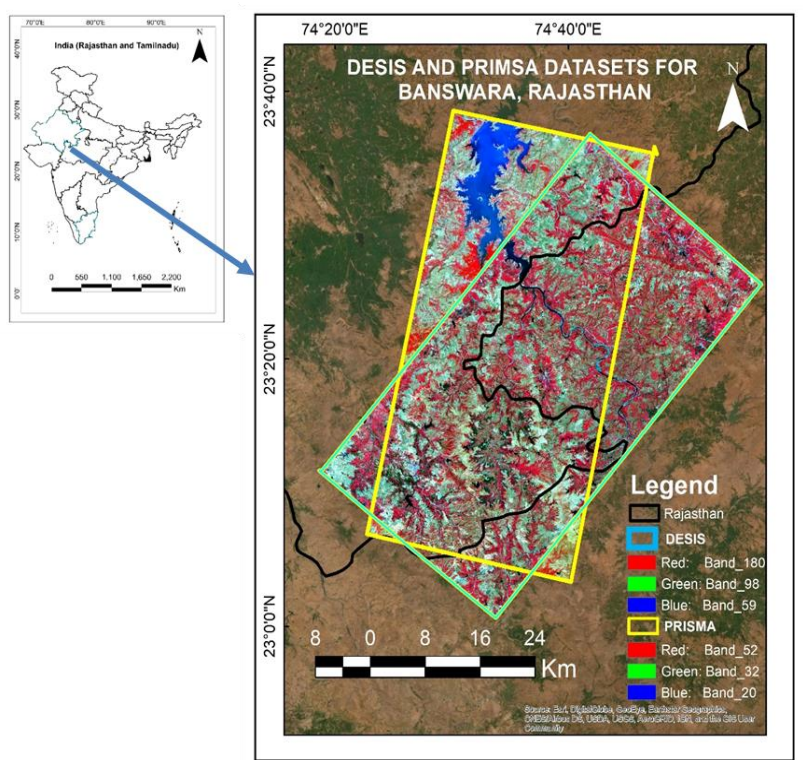

Figure 1. Study area- Banswara district of Rajasthan and Ratlam District of Madhya Pradesh State, India

As shown in Figure 1, this study utilizes the DESIS and PRISMA datasets from the Indian states of Rajasthan, as this region has geological significance, especially in terms of minerals. Rajasthan is located in the north-western part of India. The State possesses a variety of lithological and tectonic units ranging from the Archaean age to Recent times. The study area includes the Banswara region of Rajasthan state stretching 
between $23^{\circ} 03^{\prime}$ to $23^{\circ} 56^{\prime} \mathrm{N}$ latitude and $73^{\circ} 57^{\prime}$ to $74^{\circ} 47^{\prime} \mathrm{E}$ longitude. The study area has a variety of lithological units, as shown in Figure 2. The minerals found here are mica schist, phyllite, conglomerate, crystalline limestone, dolomite, intrusive, ultrabasic rock, granite gneiss, and alluvium (Gupta, 1934; Heron, 1935).

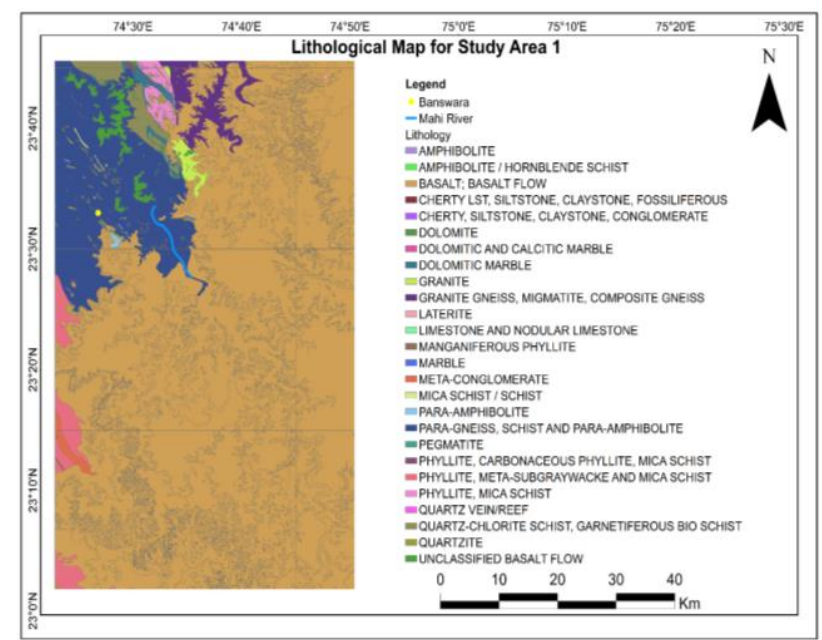

Figure 2. Lithological Map for the Study area

\section{RESULTS}

On comparing with lithological Map, the results of various data dimensionality reduction or feature extraction techniques show some interesting results for the geology of the study area. We have generated few Indices based on PCA, MNF, and ICA results. On comparing with Lithological Map, few patches of granite, basalt, mica schist, and quartzite are seen in Figure 3(a) and (b). These interpretations may not be accurate but give an overall idea about the regional geology. For Figure 4(a), the MNF component 4 gives a rough idea about the presence of muscovite in the lower part of the image (Kushalgarh, Rajasthan).
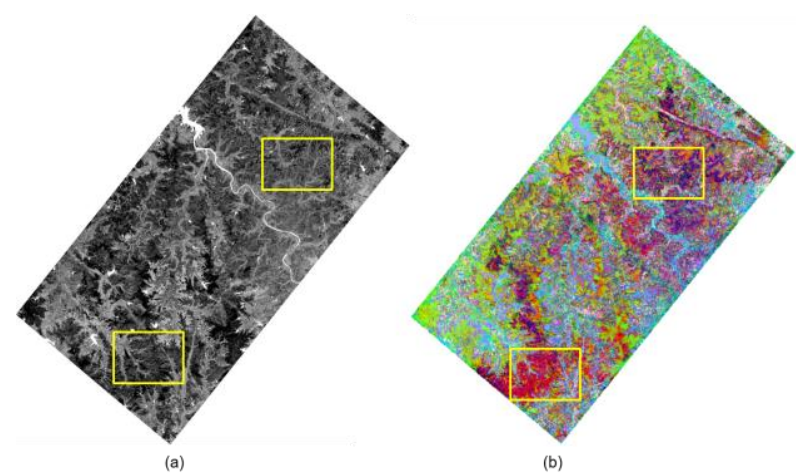

Figure 3. DESIS datasets (a) PC 3 (b) PC Indices $R=7 \quad G=4$ $\mathrm{B}=3$
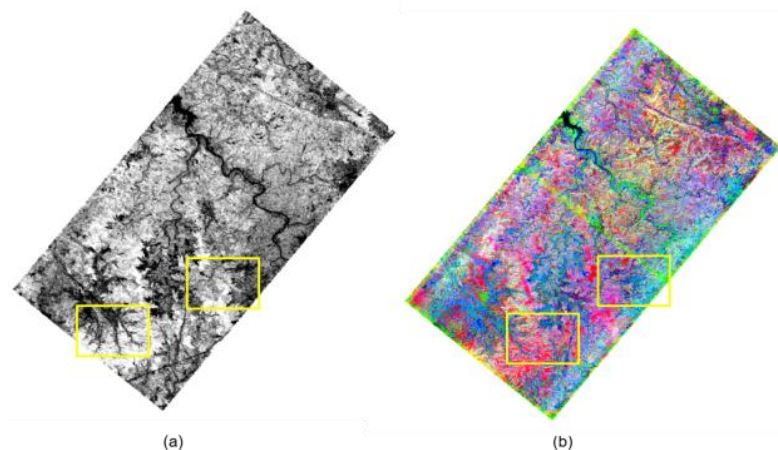

Figure 4. DESIS datasets (a) MNF 4 (b) MNF Indices $R=3$ $\mathrm{G}=9 \quad \mathrm{~B}=7$
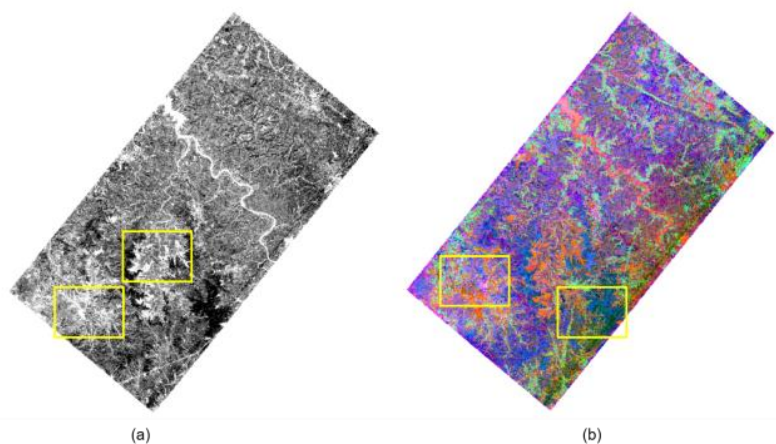

(b)

Figure 5. DESIS datasets (a) IC 3 (b) IC Indices $R=2 \quad G=3 \quad B=4$

In contrast, in Figure 4(b), MNF Indices $R=3 \quad G=9 \quad B=7$, areas with basalts are matched in pink and blue. ICA is applied on DESIS datasets, and IC component 3 and indices consisting of IC components as $\mathrm{R}=2 \mathrm{G}=3 \mathrm{~B}=4$ are shown in Figure 5. These results support PCA and MNF results on DESIS data in interpreting the minerals like muscovite, granite, and mostly basalts. Figure 5(a) shows the bright patches in the yellow box show the similarity with mica schist and basalt while in Figure 5(b) the blue and light green color on the bottom of the image shows basalt flow.

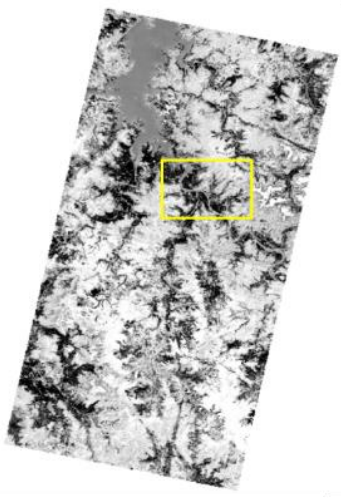

(a)

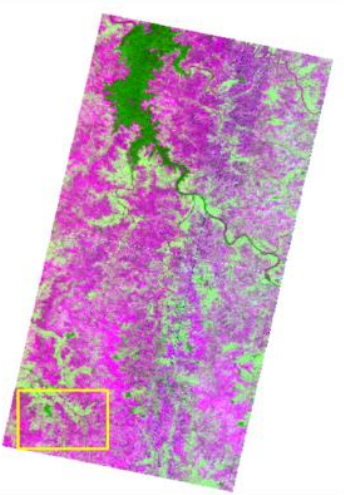

(b)
Figure 6. PRISMA datasets (a) PC 3 (b) PC Indices R=10 G=7 $\mathrm{B}=1$ 


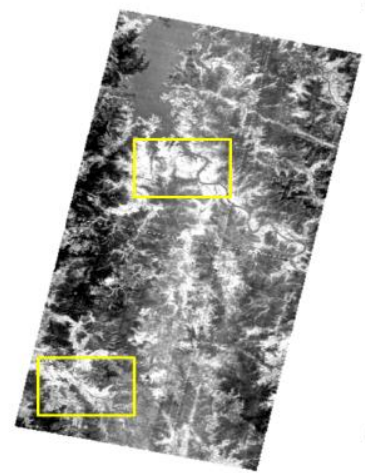

(a)

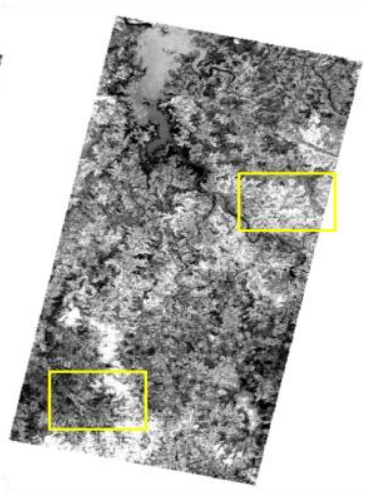

(b)
Figure 7. PRISMA datasets (a) MNF 2 (b) MNF 4

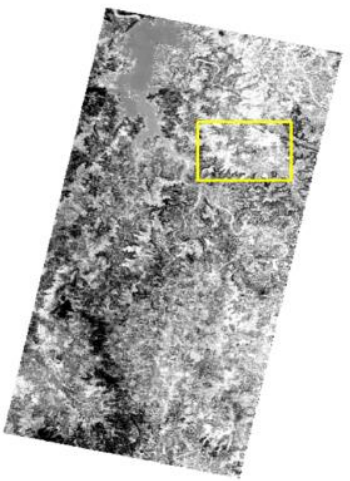

(a)

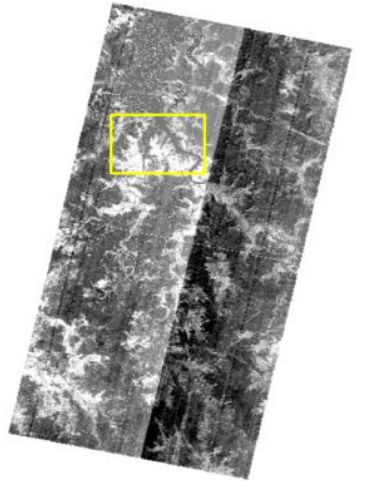

(b)
Figure 8. PRISMA datasets (a) IC 4 (b) IC 5

A similar methodology was followed for PRISMA hyperspectral datasets. However, the interpretation here was expected to be far better than DESIS provided an extended wavelength range. Due to the striping error in SWIR bands, understanding geological features is impossible for a few of the band indices or components. In Figure 6(a) and (b), on comparing with lithological Map, few patches for granite and basaltic schist are seen. Striping error, however, made it difficult to say whether the central areas are representing some geological outcrops or not. In Figure 7(a) and (b), components 2 and 4 of MNF are shown, and few patches of granite and basaltic rocks are seen (marked in yellow boxes). Few patches of basalts and other minerals are mixed. Figure 8(a) and (b), ICA components 4 and 5 are shown for PRISMA hyperspectral datasets. Here striping error, error due illumination dominates the results, so the only interpretation possible here is basalts (in yellow boxes). Table 2 enlists the narrowband ratios which are also shown in Figure 9(a) and (b) reveal granite, composite granite, basalts, and amphiboles, including hornblende schist.

\begin{tabular}{|c|c|c|}
\hline Band Ratio & $\begin{array}{c}\text { Original Band } \\
\text { Ratio/Indices }\end{array}$ & $\begin{array}{c}\text { Band Ratio/Indices } \\
\text { for PRSIMA }\end{array}$ \\
\hline $\begin{array}{c}\text { Amphibole } \\
\text { Band Ratio }\end{array}$ & $\begin{array}{c}\text { Band6 + Band 9)/ } \\
\text { Band 8 }\end{array}$ & $\left(\mathrm{R}_{1650}+\mathrm{R}_{2398}\right) / \mathrm{R}_{2345}$ \\
\hline $\begin{array}{c}\text { Modified } \\
\text { Clay and } \\
\text { Iron Band } \\
\text { Ratio }\end{array}$ & $\begin{array}{c}(\text { Band5 * Band 7)/ } \\
(\text { Band 6) }\end{array}$ & $\left(\left(\mathrm{R}_{2165} * \mathrm{R}_{2260}\right) /\right.$ \\
$\left(\mathrm{R}_{2205}\right)^{2}+$ \\
$\left.\left(\mathrm{R}_{2165} / \mathrm{R}_{1650}\right)\right)$
\end{tabular}

Table 2. Narrowband Ratio for PRISMA

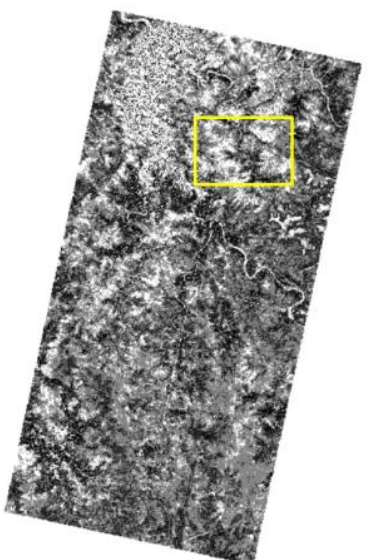

(a)

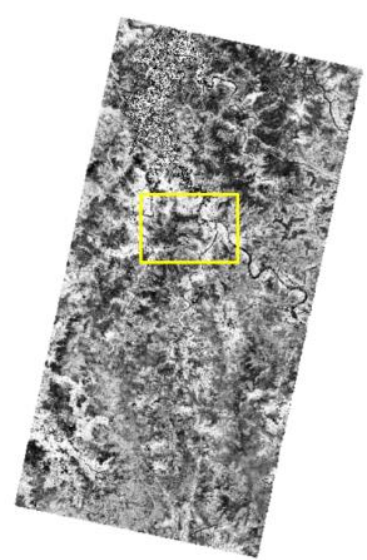

(b)
Figure 9. Narrowband Indices for PRISMA (Modified from ASTER band ratios) (a) Clay and Iron narrowband ratio (b) Amphibole narrowband ratio

\section{DISCUSSIONS AND CONCLUSION}

Data dimensionality techniques are beneficial in estimating mineral abundance areas. Spectral binning in DESIS helps extract various diagnostic absorption features but, on the other hand, mix many absorption features. Striping Error in PRISMA affecting the results of data dimensionality reduction Band ratios generated can be very helpful in mineral mapping. The mineral mapping of an area based on data dimensionality reduction or feature extraction of a hyperspectral image mostly depends on how much geological area is present or visible in the hyperspectral imagery. Hence the acquisition time is vital for his type of work. The study area chosen here is primarily a large geological area and is also proved in most of the results, excluding those affected by striping or illumination error. The future work will include the compression of newly launched PRISMA hyperspectral datasets. A kernel-based normalized PCA using the SVD decomposition technique is in progress.

\section{ACKNOWLEDGEMENTS}

We want to thank the Italian Space Agency (ASI) and German Space Agency (DLR) for providing access to PRISMA and DESIS data.

\section{REFERENCES}

Boardman, J.W., Kruse, F.A., 1994. Automated spectral analysis: a geological example using AVIRIS data, north Grapevine Mountains, Nevada: in Proceedings, ERIM Tenth Thematic Conference on Geologic Remote Sensing. Environ. Res. Inst. Michigan, Ann Arbor, MI, pp. I-407-I-418.

Chuvieco, E., 2016. Fundamentals of satellite remote sensing: an environmental approach. CRC Press.

Green, A.A., Berman, M., Switzer, P., Craig, M.D., 1988. A transformation for ordering multispectral data in terms of image quality with implications for noise removal. IEEE Trans. Geosci. Remote Sens. 26, pp. 65-74.

Gupta, B.C., 1934. The Geology of the Central Mewar, Memoir of the Geological Survey of India, 65, pp. 2. Office of the Geological Survey of India, New Delhi. 
Gupta, P., Venkatesan, M., 2020. Mineral identification using unsupervised classification from hyperspectral data, in: Emerging Research in Data Engineering Systems and Computer Communications. Springer, pp. 259-268.

Harsanyi, J.C., Chang, C.-I., 1994. Hyperspectral image classification and dimensionality reduction: An orthogonal subspace projection approach. IEEE Trans. Geosci. Remote Sens. 32, pp. 779-785.

Heron, A.M., 1935. The Pre-Vindhyan Geology of Rajputana. Curr. Sci. 13, pp. 889-895.

Hyvarinen, A., 1999. Fast and robust fixed-point algorithms for independent component analysis. IEEE Trans. Neural Networks 10, pp.626-634.

Hyvärinen, A., Oja, E., 2000. Independent component analysis: algorithms and applications. Neural networks 13, pp. 411-430.

Kalinowski, A., Oliver, S., 2004. ASTER Mineral Index Processing Manual Compiled by Aleks Kalinowski. Remote Sens. Appl. Geosci. Aust. 37, pp.36-37.

Kerr, G., Avbelj, J., Carmona, E., Eckardt, A., Gerasch, B., Graham, L., Günther, B., Heiden, U., Krutz, D., Krawczyk, H., Makarau, A., Miller, R., Müller, R., Perkins, R., Walter, I., 2016. The hyperspectral sensor DESIS on MUSES: Processing and applications, in: 2016 IEEE International Geoscience and Remote Sensing Symposium (IGARSS). pp. 268-271.

Krutz, D., Müller, R., Knodt, U., Günther, B., Walter, I., Sebastian, I., Säuberlich, T., Reulke, R., Carmona, E., Eckardt, A., Venus, H., Fischer, C., Zender, B., Arloth, S., Lieder, M., Neidhardt, M., Grote, U., Schrandt, F., Gelmi, S., Wojtkowiak, A., 2019. The Instrument Design of the DLR Earth Sensing Imaging Spectrometer (DESIS). Sensors, pp. 19-20.

Loizzo, R., Guarini, R., Longo, F., Scopa, T., Formaro, R., Facchinetti, C., Varacalli, G., 2018. Prisma: The Italian hyperspectral mission, in: International Geoscience and Remote Sensing Symposium (IGARSS). Institute of Electrical and Electronics Engineers Inc., Valencia, pp. 175-178.

Pour, A.B., Park, Y., Park, T.-Y.S., Hong, J.K., Hashim, M., Woo, J., Ayoobi, I., 2019. Evaluation of ICA and CEM algorithms with Landsat-8/ASTER data for geological mapping in inaccessible regions. Geocarto Int. 34, pp. 785-816.

Richards, John Alan, Richards, J A, 1999. Remote sensing digital image analysis. Springer.

Rodarmel, C., Shan, J., 2002. Principal component analysis for hyperspectral image classification. Surv. L. Inf. Sci. 62, pp. $115-122$.

Samani, P., Prizomwala, S.P., Rajawat, A.S., 2020. Assessing the Mineral Alteration in Ambaji-Deri Region (Northwestern India) Using Hyperspectral Remote Sensing. J. Indian Soc. Remote Sens. pp. 2-3.

Shirmard, H., Farahbakhsh, E., Pour, A.B., Muslim, A.M., Dietmar Müller, R., Chandra, R., 2020. Integration of selective dimensionality reduction techniques for mineral exploration using ASTER satellite data. Remote Sens. pp. 12-13.
Stefano, P., Angelo, P., Simone, P., Filomena, R., Federico, S., Tiziana, S., Umberto, A., Vincenzo, C., Acito, N., Marco, D., Stefania, M., Giovanni, C., Raffaele, C., Roberto, D.B., Giovanni, L., Cristina, A., 2013. The PRISMA hyperspectral mission: Science activities and opportunities for agriculture and land monitoring, in: International Geoscience and Remote Sensing Symposium (IGARSS). pp. 4558-4561.

Uddin, M.P., Mamun, M. Al, Hossain, M.A., 2020. PCA-based Feature Reduction for Hyperspectral Remote Sensing Image Classification. IETE Tech. Rev. (Institution Electron. Telecommun. Eng. India) 10, pp. 1-21.

van der Meer, F.D., van der Werff, H.M.A., van Ruitenbeek, F.J.A., Hecker, C.A., Bakker, W.H., Noomen, M.F., van der Meijde, M., Carranza, E.J.M., de Smeth, J.B., Woldai, T., 2012. Multi- and hyperspectral geologic remote sensing: A review. Int. J. Appl. Earth Obs. Geoinf. 14, pp. 112-128. 